\title{
CONTRA A MORTE DEFINITIVA: O LIVRO DOS MORTOS COMO UM GUIA DE MEMÓ- RIA NO ALÉM
}

\author{
Prof. Ms. Keidy Narelly Costa Matias ${ }^{l}$
}

\begin{abstract}
Resumo: $\mathrm{O}$ presente texto traz uma discussão acerca do lugar da memória na sociedade egípcia a partir da análise de algumas passagens do Livro dos Mortos de Ani (c. 1275 a.C.); para além da memória dos vivos - necessária à perpetuidade do nome do morto - era necessário que o próprio morto, um Osíris, soubesse acerca dos caminhos os quais deveria seguir, de modo a capacitar-se no sentido de garantir a continuidade de sua existência no Além, vencendo a "segunda morte" (não existência) - aquela definitiva.

Palavras-chaveः memória, negação da morte, Livro dos Mortos.
\end{abstract}

A antiga religião egípcia era caracterizada pela sua fusão com a magia; devemos tratá-la como elemento mágico-religioso. Outrossim, muitas manifestações rituais eram conhecidas no Egito - tanto nas celebrações da vida quanto naquelas relativas ao culto funerário. A sociedade egípcia era quase que completamente ritualizada. Como ritual, entendemos toda e qualquer manifestação simbólica dotada de alguma repetição (ritmo) ligada às dimensões mágico-religiosas. Por sua vez, às dinâmicas diárias que não se correlacionam diretamente com manifestações religiosas per se atribuímos o conceito de vida cotidiana.

Em suas múltiplas esferas - cívicas, artísticas religiosas etc. - a sociedade egípcia procurava legitimação para suas ações através de constantes referências aos momentos primevos da criação do mundo, idealizado pelos deuses $\mathrm{e}$ governado por eles próprios até a criação do homem. A sociedade se modificava lentamente, porém, não por inércia: mas sim através de constantes alusões à necessidade de um mundo ordenado, personificado pela deusa "Maat" - que

1 Mestre em História e Espaços pela Universidade Federal do Rio Grande do Norte (UFRN), estudante pesquisadora da Cátedra UNESCO Archai, da UnB, e integrante do MAAT - Núcleo de Estudo de História Antiga da UFRN, coordenado pela profa. Dra. Marcia Severina Vasques. Email: keidylmatias@gmail.com 
pode também ser interpretada como um princípio cujas associações mais próximas se referem aos ideais de "verdade, justiça e equilíbrio", fulcrais ao modus vivendi egípcio; a manifestação contrária ao princípio de Maat era a própria representação das forças do caos (Isfet), ou seja, da desordem.

[O] papel [de Maat] era multifacetado, mas caracterizado por dois aspectos principais. Por um lado, Maat representava a ordem ou a balança universal - incluindo conceitos como verdade e justiça - que foram estabelecidos desde o momento da criação. Essa característica é a base de seu relacionamento com Rê, pois ela é a própria ordem imposta sobre o universo criado pelo demiurgo solar e, como tal, é também o princípio orientador que acompanhou o deus sol em todos os tempos. A ordem representada por Maat deve ser renovada ou preservada constantemente. [...] Maat também representou ativamente o conceito de julgamento (WILKINSON, 2003, p. 150).

A arte egípcia - de caráter funcional - tinha por fim documentar o todo, dado que o desenho retratado de uma pessoa era a sua própria manifestação; qualquer rasura em uma parede mural, por exemplo, atuava no sentido de deturpar e, de maneira mais trágica, de apagar a memória do homem dela dependente; era uma ameaça de aniquilação da própria continuação da existência na Duat - denominação do espaço dos mortos no recorte temporal que estamos tratando, o Novo Império (1550 - 1075 a.C.), com ênfase na XIX Dinastia (1291 - 1185 a.C.). Uma estátua funerária era também o próprio morto; em caso de deformação dessa representação, magicamente o homem morto também se deformava; por exemplo, se uma estátua apresentasse o nariz extraído, o morto poderia enfrentar o caos de viver eternamente sem esse sentido. Outrossim, o caráter mágico da religião garantia que uma prótese ou o próprio verbo (uma ação) poderia atuar no sentido de restituir quaisquer membros ou sentidos perdidos pelo morto.

Além do poder da arte havia o poder do verbo: o "nome" (ren) de uma pessoa era um dos sete elementos que a compunham - os outros seis elementos eram o "corpo" (khat), a "sombra" (shut), o "coração" (ib), o "princípio estático" (ka), o "princípio dinâmico" (ba) e o "espírito glorificado" (akb), conforme aponta Claude Traunecker (1995, p. 33-35) - destacamos que a simplicidade das traduções dessas terminologias não é condizente com as suas respectivas complexidades, tópico que não adentraremos neste texto. Retomando, pronunciar o nome de um morto era também uma maneira de não o deixar cair em terrível esquecimento, visto que tal condição era uma das maneiras de se "morrer uma segunda vez". Saber o nome de alguém era também uma forma de detenção de poder, pois fazer menção a um nome era um exercício 
que tanto poderia ocorrer de forma positiva quanto negativa. Desse modo, se os mortos faziam parte da sociedade dos vivos, não é precipitado inferir que os vivos faziam parte da sociedade dos mortos.

As constantes referências à criação, elas mesmas tentativas de manter o princípio de Maat, conferiam à sociedade um caráter ordenado, mas que não impedia a existência de inovações, sobretudo, na utilização de novos suportes para a propagação de velhas fórmulas.

A arte egípcia que não hesita em se apresentar como bastante convencional em sua aspiração fundamental, que deveria de algum modo manter os modelos dos primeiros tempos, na realidade os atualiza adaptando-se constantemente às necessidades em perpétua transformação.

[...] Ao longo de três mil anos de história da civilização egípcia os criadores nunca deixaram de encontrar soluçóes novas, respeitando a perene ideia essencial subjacente da perfeita adequação entre a obra e sua função (BRANCAGLION, 2003, p. 8-9).

O "Livro para Sair à Luz do Dia", que na modernidade ficou conhecido como "Livro dos Mortos", foi uma dessas inovações - essa denominação moderna data de 1842, quando Karl Richard Lepsius, egiptólogo alemão, publicou Das Todtenbuch der Ägypter. Acredita-se que o egiptólogo tenha feito uma adaptação do nome já utilizado pelos egípcios para se referirem ao livro que ficava junto ao morto, em árabe, kitab al-mayitūn, ou seja, "livro do defunto". Dessa maneira, aquilo que antes era retratado nas paredes das pirâmides, no Antigo Império (c. de 2575 - 2150 a.C.), passou a ser documentado majoritariamente nos sarcófagos, durante o Primeiro Período Intermediário (c. de 2150 - 2040 a.C.) e o Médio Império (c. de 2040 - 1640 a.C.), e em seguida nos papiros, a partir de finais do Segundo Período Intermediário (c. de 1640 - 1550 a.C.) e inícios do Novo Império (c. de 1550-1070 a.C.), com exemplares cuja datação se estende até o Período Romano (30 a.C. 313 d.C.). Esses três conjuntos de textos propiciaram a existência do que se convencionou chamar, respectivamente, de "Textos das Pirâmides", "Textos dos Sarcófagos" e "Livro dos Mortos".

Nossa fonte é datada da XIX Dinastia (1291 - 1185 a.C.); trata-se do Livro dos Mortos de Ani ou Papiro de Ani (Museu Britânico/EA 10470/3.), adquirido pelo British Museum através do egiptólogo Sir Ernest Wallis Budge (1857 - 1934), seu então curador de antiguidades egípcias. Budge foi o primeiro tradutor do Papiro de Ani (a publicação data de 1895); interessa destacar que, nessa publicação, o britânico se notabilizou pela tentativa de 
sistematização do Livro dos Mortos por meio da utilização de outras fontes, por exemplo, do Papiro de Hunefer (c. 1275 a.C.). Em outras palavras, Budge objetivou completar a totalidade de fórmulas do Livro dos Mortos em uma só publicação: o Papiro de Ani possui sessenta e cinco fórmulas (65); a totalidade de fórmulas conhecidas do Livro dos Mortos é de cento e noventa e duas (192), cujas escolham variavam de exemplar para exemplar. A escolha das fórmulas se modificava conforme a tradição: alguns capítulos eram mais recorrentes do que outros em determinados períodos. Em resumo, objetivando publicar todas as 192 fórmulas do Livro dos Mortos, Budge se utilizou dos 65 encantamentos presentes no Papiro de Ani e complementou a publicação com os outros capítulos retirados de fontes variadas.

A sequência canônica na qual certos encantamentos foram agrupados foi, em grande medida, constituída na 26 $6^{\mathrm{a}}$ Dinastia. Duplicações de encantamentos ocorriam em muitos manuscritos. $\mathrm{O}$ número de fórmulas empregadas varia consideravelmente: o papiro de Kha, em Turim, contém 33, o de Yuya [contém] 41, o de Ani, 65, e o de Nu, em Londres, 137 (HORNUNG, 1999, p. 17).

O Livro nos oferece um sem número de possibilidades e, no que se refere à abordagem acerca do conceito de memória, não é destoante; para isso, escolhemos dois capítulos do Livro dos Mortos para tratarmos sobre a importância da manutenção da memória no Egito Antigo:

a) Capítulo 125: "As declarações de inocência diante dos deuses no tribunal";

b) o Capítulo 30b: “De como não deixar o coração de Ani criar oposição contra ele nos domínios do deus".

Podemos apontar didaticamente que o Livro dos Mortos de Ani se inicia com dois hinos de adoração, respectivamente, direcionados aos deuses Rê e Osíris. Em seguida, apresenta o Capítulo 30b, uma de suas fórmulas mais conhecidas. A ordem de aparição das fórmulas no Livro não necessariamente era a mesma em que as situações magicamente ocorriam as "Confissóes Negativas" (Cap. 125) provavelmente eram proferidas antes da pesagem do coração do morto no tribunal de Osíris (Cap. 30b).

\section{UM GUIA DE MEMÓRIA}

Podemos pensar no Livro dos Mortos como uma "memória externa", tal como coloca Frances Yates (1966, p. 22), que nos alerta sobre a importância da memória artificial, "fundada em lugares e imagens [...], definição fundamental 
que se há de repetir sempre em diferentes épocas". Partindo desta acepção, o Livro dos Mortos pode ser pensado como um guia de memória, ou seja, como um auxílio necessário ao morto para que ele próprio pudesse evitar o esquecimento dos nomes e caminhos indispensáveis aos domínios fundamentais da lembrança no post-mortem. Sua natureza enquanto guia de memória para o morto é inequívoca.

Ademais, mesmo não se constituindo como preocupação central neste texto, interessa destacar que o Livro é bastante polissêmico.

No Egito Antigo, a realização dos rituais funerários era fundamental tanto para que a perda fosse demarcada (para os vivos) quanto para evitar que o morto se tornasse uma assombração - se os rituais não ocorressem, o morto vagaria como um fantasma assombrando os vivos (CANHÃO, 2012; TRAUNECKER, 1995.). Em suma, os ritos eram imprescindíveis para que a continuação da vida no mundo dos mortos - domínio do deus Osíris ocorresse em sua plenitude. $\mathrm{O}$ morto dependia dos vivos, que faziam oferendas em sua tumba e preservavam-lhe o nome, fazendo com que sua existência fosse perpetuada, mas também dependia de si mesmo: para que sua memória fosse eternizada era fundamental que ele, o morto, contivesse memória. É nesse contexto que o Livro dos Mortos pode ser considerado um guia, pois se tratava de uma mídia fundamental no sentido de fazer o morto lembrar-se dos encantamentos necessários ao sucesso de sua caminhada na Duat.

Weinrich (2001) nos faz associar a memória à vida, sobretudo, quando coloca Léthe $(\Lambda \eta ́ \theta \eta)$ como algo "letal", o esquecimento. No Egito Antigo, a morte do corpo físico (khat) não eliminava a sua continuidade no mundo dos mortos, que ocorria também por intermédio do seu ba - "princípio da energia que permanece no corpo mesmo depois de encerradas as funções vitais" (DUNAND; ZIVIE-COCHE, 2003, p.189).

O ba ou "alma" era um dos elementos constitutivos da personalidade humana, que se separava por ocasião da morte. Era representado como um falcão com cabeça humana e, eventualmente, braços. $\mathrm{Na}$ forma do ba, o morto percorria o mundo dos mortos, ia à Sala do Julgamento, aos Campos de Juncos e de Oferendas e viajava na barca solar. À noite, o ba voltava para junto da múmia (ASSMANN, 2003, p. 149 apud VASQUES, 2005, p. 68). 
A realização do ritual de mumificação recebia contornos fundamentais, pois reconhecer-se no além era uma pré-condição vital à perpetuidade da existência; não se reconhecer era não ter repouso, era não se encontrar consigo mesmo: a perda da memória tinha, portanto, como consequência mais urgente a perda do lugar e da identidade social do morto na Duat. Não ter memória significava estar susceptível a uma "segunda morte"; esta, por sua vez, desencadeadora da condição egípcia de não existência.

[A] segunda morte era causada pela condenação da alma pelo tribunal divino diante de Osíris, pela incapacidade do morto em mover-se no Outro Mundo e pela perda do nome (memória). Portanto a segunda morte reporta-se à falta de condições que permitam à alma sobreviver, pois o corpo já se encontrava inanimado pela primeira morte.

A morte em si não é capaz de colocar fim ou abreviar a existência a não ser de maneira parcial, a morte do corpo físico. Ela era acompanhada sempre de um grande perigo, o de extinguir a existência da alma, esta eventualidade deveria ser afastada com precauções na forma de fórmulas mágicas, amuletos e ritos bem determinados pelo Corpus Religioso (BRANCAGLION, 2003b, p. 13).

Em síntese, desde o Antigo Império os egípcios desenvolveram fórmulas que tinham por fim atuar na manutenção da vida através da perpetuação da memória; essas fórmulas foram perpassadas por muitos suportes, notadamente, as paredes das pirâmides, os caixóes e os papiros. O Livro dos Mortos era um guia que propiciava ao morto lembrar-se de si mesmo, de modo que ele próprio pudesse ter conhecimento dos seus caminhos na Duat.

\subsection{As vinhetas}

Doravante, propomo-nos a elencar e a discutir duas vinhetas do Livro dos Mortos que apresentam as ideias referentes ao conceito de memória. Interessa destacar que não é nossa intenção analisar as cenas, mas tão somente discuti-las à luz daquilo que fora apresentado.

\subsubsection{Capítulo 125: Confissões Negativas ou Declarações de Inocência}

As Confissóes Negativas (Figs. 1 e 2) são o conjunto de quarenta e dois (42) encantamentos que tinha por finalidade assegurar a absolvição do morto diante de pretensas acusações, sendo a negação dessas acusações de natureza fundamental para o garante da continuação da existência no além. Interessa destacar que essas fórmulas não eram inventadas pelo morto, mas sim constituíam parte de uma tradição. Considerando a função mágica do 
verbo, as fórmulas atuariam no sentido de restituir a ordem na medida em que sua pronúncia conferia ao morto determinada segurança diante daquilo que mais o amedrontava: deixar de existir. Enfatizava-se que não se havia cometido dados desvios de conduta mesmo que, quando em vida, o morto os tivesse praticado, haja vista que o ato de estar escrito o inocentava.

O morto se portava diante dos guardióes da Duat; ele precisava professar corretamente o nome de cada um, bem como confessar o que não havia feito de errado; a inocência se dava a partir da negação. Cada guardião escutava uma declaração de inocência, sendo a lembrança do encantamento e sua pronúncia as chaves da absolvição. Para rememorar esses encantamentos era que o morto lançava mão do Livro dos Mortos.

A seguir, uma relação das Confissões Negativas presentes no Papiro de Ani; optamos por mostrar apenas as declarações de inocência, sem a nomenclatura de cada guardião que antecede os dizeres aqui expostos:

$1^{a}[\ldots]$ Eu não fiz nada de errado;

$2^{\mathrm{a}}[\ldots]$ Eu não roubei;

$3^{\mathrm{a}}[\ldots]$ Eu não furtei;

$4^{\mathrm{a}}[\ldots]$ Eu não matei pessoas;

$5^{\mathrm{a}}[\ldots]$ Eu não destruí as oferendas de alimentos;

$6^{\mathrm{a}}[$...] Eu não reduzi as medidas [dos grãos];

$7^{\mathrm{a}}[\ldots]$ Eu não furtei a propriedade do deus;

$8^{a}[\ldots]$ Eu não falei mentiras;

$9^{\mathrm{a}}[\ldots]$ Eu não fui carrancudo;

$10^{\mathrm{a}}[\ldots]$ Eu não forniquei com o fornicador (?);

$11^{\mathrm{a}}[\ldots]$ Eu não fiz ninguém chorar;

$12^{\mathrm{a}}[\ldots]$ Eu não dissimulei;

$13^{\mathrm{a}}[\ldots]$ Eu não transgredi;

$14^{a}[$ [... Eu não cometi especulação de grãos;

$15^{\mathrm{a}}[\ldots]$ Eu não roubei uma parcela de terra;

$16^{a}[$ [...] Eu não contei ou discuti segredos (não tagarelei; não espalhei segredos);

$17^{a}[\ldots]$ Eu não provoquei uma ação judicial;

$18^{\mathrm{a}}[\ldots]$ Eu não disputei propriedades;

$19^{a}[$ [...] Eu não tive relações sexuais com uma mulher casada (eu não cometi adultério);

$20^{\mathrm{a}}[$ [... Eu não copulei erradamente (?);

$21^{a}[\ldots]$ Eu não fiz [as pessoas sentirem] medo;

$22^{\mathrm{a}}[\ldots]$ Eu não transgredi;

$23^{\mathrm{a}}[\ldots]$ Eu não fui destemperado;

$24^{a}$ [...] Eu não ocultei a verdade;

$25^{a}[\ldots]$ Eu não amaldiçoei;

$26^{a}[\ldots]$ Eu não fui violento; 
$27^{\mathrm{a}}[. .$.$] Eu não distorci a verdade;$

$28^{a}$ [...] Eu não fui impaciente;

$29^{a}$ [...] Eu não discuti (não duvidei);

$30^{\mathrm{a}}$ [...] Eu não tagarelei sobre assuntos;

$31^{\text {a }}$ [... $]$ Eu não fiz nada errado;

$32^{a}$ [...] Eu não cometi o mal.

$33^{\text {a }}$ [... $]$ Eu não contestei o rei;

$34^{\mathrm{a}}[\ldots]$ Eu não profanei a água

$35^{\mathrm{a}}$ [...] Eu não falei alto;

$36^{\mathrm{a}}$ [...] Eu não amaldiçoei a um deus;

$37^{\text {a }}$ [... $]$ Eu não exaltei a mim mesmo (eu não fiz autoexaltação);

$38^{\text {a }}$ [...] Eu não profanei a comida dos deuses;

$39^{a}$ [...] Eu não furtei os bolos-Khenef (oferendas) dos [mortos] santificados;

$40^{\mathrm{a}}$ [... $]$ Eu não furtei os bolos-Hefnu de uma criança (eu não tirei comida da boca de uma criança);

$41^{\mathrm{a}}[\ldots]$ Eu não prendi um deus na minha cidade;

$42^{\text {a }}[\ldots]$ Eu não matei o gado sagrado.

"No capítulo 125, o morto não era o requerente, mas sim o acusado; ele tinha de justificar-se perante os juízes divinos, recitando uma longa lista de potenciais transgressões e atestando que não havia cometido-as" (ASSMANN, 2005, p. 75). Para que esses 42 encantamentos fossem verbalizados era preciso tê-los em mente; visando não se arriscar diante dessa dificuldade imposta pela memória, o morto se munia do Livro dos Mortos como um guia. Finalmente, em consonância com Assmann (2005) podemos ainda sugerir que as Confissões Negativas eram um reflexo das regras morais da sociedade egípcia que, por sua vez, não tinha um corpus de leis estipulado, como ocorria, por exemplo, em algumas cidades da Mesopotâmia.

1.1.2. Capítulo 30b: De como não deixar o coração de Ani criar oposição contra ele nos domínios do deus

O segundo capítulo que apresentamos é um dos mais conhecidos do Livro dos Mortos; trata-se da pesagem do coração do morto contra a pluma da deusa Maat (Fig. 3). O equilíbrio deveria prevalecer neste episódio; o coração e a pluma de Maat deveriam estar equiparados, pois isso representava o restabelecimento da ordem perdida quando da morte do corpo físico - caso fosse aprovado o morto era declarado "justo de voz" e estava apto a entrar nos domínios do deus Osíris (Fig.4). Não ser aprovado no julgamento dos mortos 
era uma das maneiras de se morrer uma segunda vez, pois a reprovação diante de Osíris ocasionava no desaparecimento total do ser - que seria devorado por um monstro híbrido chamado Ammut, a própria "personificação da segunda morte" (ASSMANN, 2005, p. 75).

O surgimento de um julgamento dos mortos a partir da imagem arcaica da morte como um inimigo foi um dos desenvolvimentos mais significativos da história da religião egípcia, e a imagem de tal julgamento era uma das ideias religiosas centrais do Egito. [...] $\mathrm{O}$ conceito de julgamento dos mortos veio a adquirir uma importância elevando-se entre as imagens da morte que influenciaram a realidade vivida dos antigos egípcios (ASSMANN, 2005, p. 73).

As Confissões Negativas bem podiam ser professadas antes da pesagem do coração, dado que não faz muito sentido se julgar "inocente" depois de ter sido declarado "justo de voz". Para entrar no mundo dos mortos era preciso se declarar inocente (Cap. 125) e depois ser aprovado no tribunal de Osíris (Cap. 30b). Erik Hornung (2002, p. 33) acentua que "por meio das 'confissões negativas' que o morto recita diante de Osíris e dos 42 juízes dos mortos, ele elimina todas as suas transgressões".

Podemos nos questionar sobre a ordem de aparição das sentenças no Livro dos Mortos na medida em que observamos que a psicostasia antecede às confissóes negativas. A ordem na qual as cenas são apresentadas no Livro dos Mortos não representa necessariamente a ordem na qual ocorriam, dado que essa necessidade de classificação é produto de nossa sociedade; no Egito Antigo esse ideal de ordenação se apresentava de outras maneiras. Aliás, interessa destacar que os capítulos do Livro dos Mortos não eram enumerados, sendo a enumeração um produto do século XIX.

$\mathrm{Na}$ primeira das vinhetas apresentadas (Fig. 3), temos a pesagem do coração contra a pluma da deusa Maat, na sala da "Dupla Maat" - entrada do paraíso osiríaco. Na segunda vinheta (Fig. 4) o morto já aparece declarado como "justo de voz", ou seja, apto a entrar em contato direto com o deus Osíris que, por sua vez, está protegido por Ísis e Néftis, deusas funerárias; Osíris Ani (o morto) está acompanhado por Hórus, filho de Osíris.

Quando indicamos que a ocorrência dessa cena era propiciada tanto por aqueles que compunham o mundo dos vivos quanto pelo próprio morto, 
em outras palavras, dizemos que caso o enterramento não acontecesse a continuação da existência não se apresentava como uma possibilidade, pois não entrar na terra era também não conhecer o deus, desse modo, os vivos tinham função central na medida em que garantiam o enterramento do morto.

Em adendo à necessidade do morto em ter posse do Livro dos Mortos, a mumificação aparece como um reflexo da necessidade de se permanecer reconhecível. Para tanto, era fundamental evitar a profanação do corpo; as mumificações dos mais abastados duravam até 70 dias, conforme Heródoto (séc. V a.C. [1985]). Outra questão central é a necessidade de morrer na terra do Egito (Kemet), pois assim a feitura tradicional dos rituais estava assegurada. Todos esses princípios remetem aos primeiros tempos: os antigos egípcios [do Novo Império] concebiam a si mesmos como um povo detentor de um grande passado, de uma história cuja preservação era necessária como mecanismo ordenador do cosmos. Assim, tradição e memória caminhavam juntas nos mundos dos vivos e dos mortos.

\section{Consideraçóes finais}

Nossa exposição trouxe questões relativas aos cânones da arte egípcia e aos seus ideais de representação - vistos como o "duplo" do ser representado - de modo a ressaltarmos a função mágica da religião que, por sua vez, era transportada à escrita. Os poderes do verbo e da imagem se coadunavam; produziam sensações e inferiam sentidos. Dessa forma, os encantamentos presentes no Livro dos Mortos apareciam como detentores de magia e de poder - e podiam se tornar manifestações mágicas no outro mundo (espaço dos mortos).

Elencamos dois capítulos do Livro dos Mortos de Ani (125 e 30b) a fim de demarcarmos a importância da realização dos ritos fúnebres. Dois vieses foram destacados: o primeiro com relação à atividade do morto enquanto sujeito agente de seu próprio destino (Cap. 125) e, de outro modo, a dependência que o morto tinha em relação aos vivos, pois era destes que aquele dependia para que fossem realizados os ritos e recebidas as oferendas necessárias à continuação da vida. Procuramos apresentar não uma análise descritiva dos dois capítulos aqui expostos do Papiro de Ani, mas sim utilizálos como exemplos que nos permitem conferir ao Livro dos Mortos também a categoria de ser um guia mnemotécnico; aliás, todas as vinhetas do Livro 
dos Mortos possuem na preservação da memória uma característica urgente. A perda da memória era o mesmo que desencontrar-se socialmente através do não reconhecimento de si, portanto, uma questão de identidade social.

O morto continuava sua existência em um espaço cartografado em seus ambientes e discursos pelo Livro dos Mortos; se o morto dependia da Duat para existir, por outro lado, a Duat precisava do morto para ser praticada, experienciada. $\mathrm{O}$ caso egípcio de tratamento da memória é sui generis, bem como o caráter polissêmico do Livro dos Mortos, todavia, é inegável a sua importância como um guia mnemônico: era preciso reconhecer a Duat e reconhecer-se nela sem nunca tê-la visto, essa era uma das mais primordiais tarefas a serem executadas - reconhecer o outro mundo nada mais era do que reconhecer a si mesmo.

Podemos sugerir, em alusão à denominação inicial do Livro dos Mortos (Livro para Sair à Luz do Dia), que este era um livro dos vivos; daqueles que almejavam continuar existindo. $\mathrm{O}$ mundo dos mortos era um espaço abstrato e, como abstração, também era uma existência que, por sua vez, era cartografada mediante fórmulas que não refletiam outra coisa senão a busca incessante pela eternidade.

\section{Anexos}

Figura 1: As Confissões Negativas.

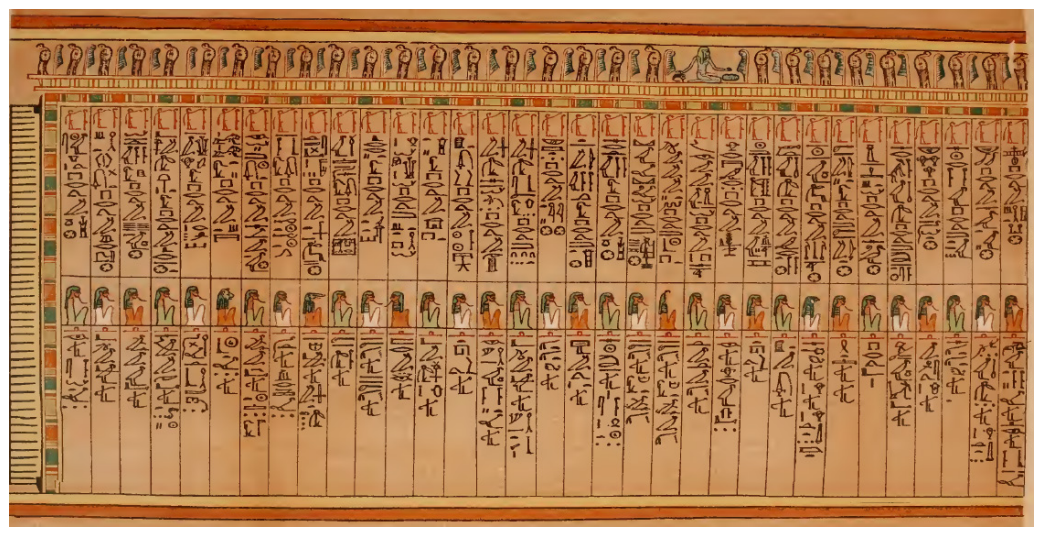

FAULKNER, Raymond. The Egyptian Book of the Dead. The Book of Going forth by Day. Trad. e comentários R. Faulkner. San Francisco: Chronicle Books, 1998, plate 31. 
Figura 2: As Confissões Negativas.

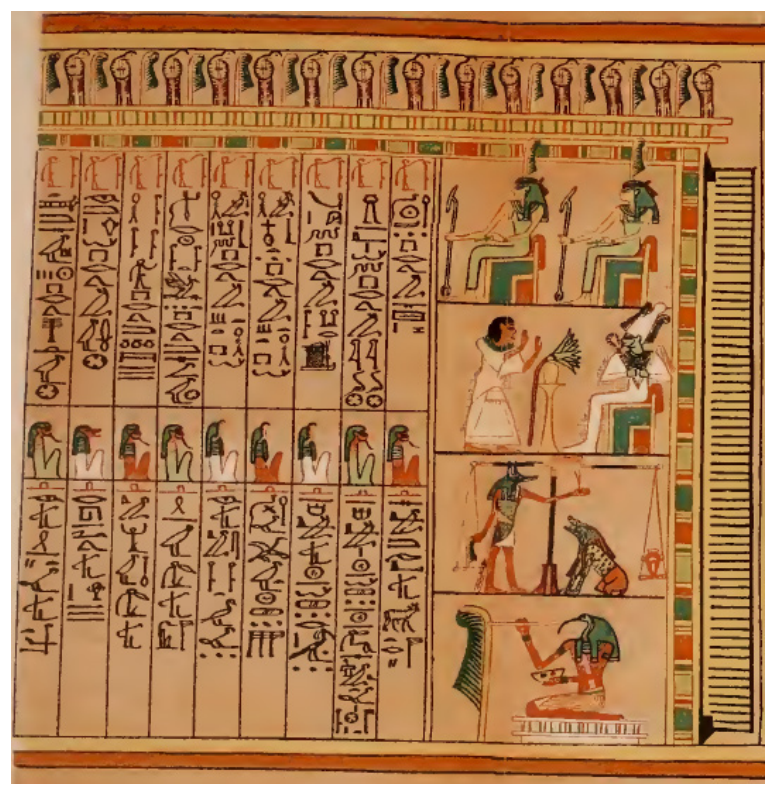

FAULKNER, Raymond. The Egyptian Book of the Dead. The Book of Going forth by Day. Trad. e comentários R. Faulkner. San Francisco: Chronicle Books, 1998, plate 31.

Figura 3: Capítulo 30b do Livro dos Mortos (cena da pesagem do coração contra a pluma da deusa Maat).

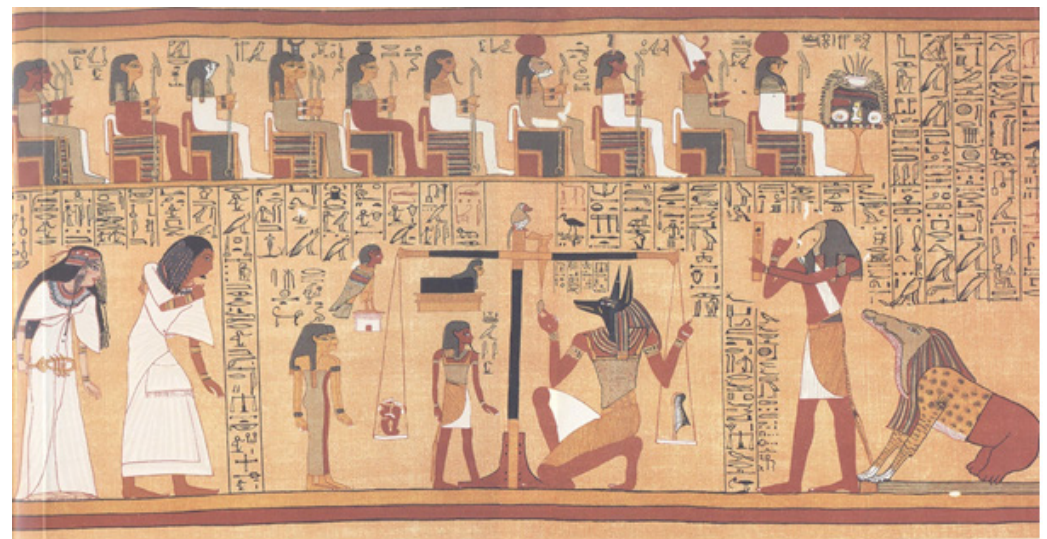

FAULKNER, Raymond. The Egyptian Book of the Dead. The Book of Going forth by Day. Trad. e comentários R. Faulkner. San Francisco: Chronicle Books, 1998, plate 3. 
Figura 4: Continuação do Capítulo $30 \mathrm{~b}$ do Livro dos Mortos. Nesta cena, o morto, Ani, aparece sendo conduzido pelo deus Hórus à presença do deus Osíris que, por sua vez, está em companhia das deusas Ísis e Néftis e diante dos quatro filhos de Hórus. $\mathrm{O}$ morto aparece ainda diante de uma mesa de oferendas, em atitude de adoração ao deus Osíris.

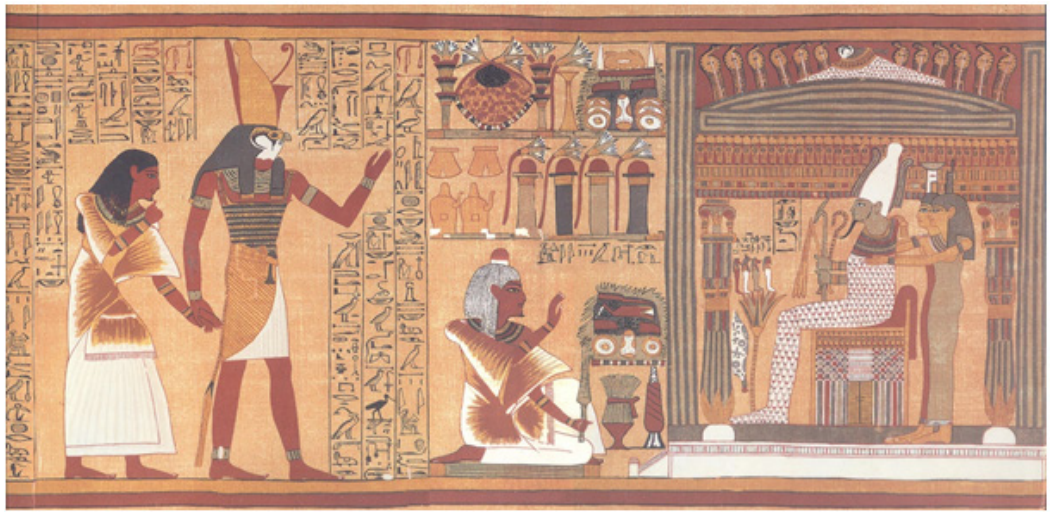

FAULKNER, Raymond. The Egyptian Book of the Dead. The Book of Going forth by Day. Trad. e comentários R. Faulkner. San Francisco: Chronicle Books, 1998, plate 4.

\begin{abstract}
This paper presents a discussion about the function of memory in Egyptian society based on the analysis of some passages from the Book of the Dead of Ani (c. 1275 b.C.); in addition to the memory of the living ones needed for the perpetuity of the name of the deceased - it was necessary for the dead person himself, an Osiris, to know about the paths which should be followed in order to become able to ensure the continuity of his/her existence in the otherworld, defeating the "second death" (nonexistence) - the definitive one.

Keywords: memory, denial of death, Book of the Dead.
\end{abstract}

\title{
REFERÊNCIAS
}

ASSMANN, Jan. Death and Salvation in Ancient Egypt. New York: Cornell University Press, 2005.

The Search for God in Ancient Egypt. New York: Cornell

University Press, 2001.

BAINES, John. Visual and Written Culture in Ancient Egypt. Oxford: Oxford University Press, 2007. 
BRANCAGLION Jr., Antonio. Manual de Arte e Arqueologia Egípcia I. Rio de Janeiro: Sociedade dos Amigos do Museu Nacional. (Série Monografias, 6). CDROOM. 2003.

. Manual de Arte e Arqueologia Egípcia II. Rio de Janeiro: Sociedade dos Amigos do Museu Nacional. (Série Monografias, 6). CD-ROOM. 2003 b.

CANHÃO, Telo Ferreira. Doze textos egípcios do Médio Império. Coimbra: Coimbra Editora, 2013.

DUNAND, François; ZIVIE-COCHE, Christiane. Dei e uomini nell'Egitto antico (3000 a.C.-395 d.C.). Roma: L'Erma di Bretschneider, 2003.

FAULKNER, Raymond. The Egyptian Book of the Dead. The Book of Going forth by Day. Trad. e comentários R. Faulkner. San Francisco: Chronicle Books, 1998. HERÓDOTO. Histórias. Trad. Mário da Gama Kury. Brasília: Ed. UnB, 1985.

HORNUNG, Erik. Conceptions of God in Ancient Egypt: The One and the Many. Ithaca: Cornell University Press, 1982.

HORNUNG, Erik. The Ancient Egyptian Books of the Afterlife. Ithaca: Cornell University Press, 1999.

HORNUNG, Erik; BRYAN, Betsy (Orgs.). The Quest for Immortalityः Treasures of Ancient Egypt. Washington: Nacional Gallery of Art, 2002.

TRAUNECKER, Claude. Os deuses egípcios. Brasília: Editora Universidade de Brasília, 1995.

WEIRICH, Harald. Lete: arte e crítica do esquecimento. Rio de janeiro: Civilização Brasileira, 2001, p.27-66.

VASQUES, Marcia Severina. Crenças funerárias e identidade cultural no Egito Romano: máscaras de múmia. 2005. 149 f. Tese (Doutorado em Arqueologia) - Museu de Arqueologia e Etnologia - USP. Universidade de São Paulo, São Paulo. 2001. Disponível em: < http://www.teses.usp.br/teses/disponiveis/71/71131/tde07082006-104608 >. Acesso em: 20 de janeiro de 2017.

WILKINSON, Richard. Symbol \& Magic in Egyptian Art. New York: Thames \& Hudson, 1994.

The Complete Gods and Goddesses of Ancient Egypt. New York: Thames \& Hudson, 2003.

YATES, Frances. El arte de la memoria. Madrid: Ediciones Siruela, 1966. 